\title{
CLEC3B as a potential diagnostic and prognostic biomarker in lung cancer and association with the immune microenvironment
}

Jiaxing Sun ${ }^{1,2 \dagger}$, Tian Xie ${ }^{1,2+}$, Muhammad Jamal ${ }^{2}$, Zhenbo Tu², Xinran $\mathrm{Li}^{3}$, Yingjie Wu ${ }^{4}$, Jingyuan $\mathrm{Li}^{2}$, Qiuping Zhang ${ }^{2}$ and Xiaoxing Huang ${ }^{1 *}$ (1)

\begin{abstract}
Background: Lung cancer is the leading cause of cancer-related mortality globally. Discovering effective biomarkers for early diagnosis and prognosis is important to reduce the mortality rate and ensure efficient therapy for lung cancer patients. C-type lectin domain family 3 member B (CLEC3B) has been reported in various cancers, but its correlation with lung cancer remains elusive.

Methods: The GEO, TCGA and Oncomine databases were analyzed to examine the expression of CLEC3B in lung cancer. The CLEC3B mRNA levels in 15 patient tissue samples were detected by real-time PCR and the CLEC3B protein levels in 34 patient tissue samples were detected by immunohistochemistry. A Chi-square test was performed to analyze the correlation of CLEC3B expression and clinicopathological factors. The diagnostic value of CLEC3B was revealed by receiver operating characteristic (ROC) curves. Univariate and multivariate Cox proportional hazards regression models and Kaplan-Meier plots were used to evaluate the prognostic value of CLEC3B in lung cancer. The TIMER database was used to evaluate the correlation of CLEC3B and immune infiltration. Gene set enrichment analysis revealed tumor-associated biological processes related to CLEC3B.
\end{abstract}

Results: CLEC3B is significantly downregulated in lung cancer patients compared with nontumor controls according to database analysis and patient tissue sample detection ( $p<0.001$ ). Specifically, CLEC3B is significantly downregulated in stage IA lung cancer patients $(\mathrm{p}<0.001)$ and has a high diagnostic accuracy (area under the receiver operating characteristic curve $>0.9$ ). Moreover, low expression of CLEC3B is related to poor progression-free survival $(H R=0.60,95 \% \mathrm{Cl} 0.49-0.74, p=8.3 e-07)$ and overall survival $(H R=0.66,95 \% \mathrm{Cl} 0.58-0.75, p=2.1 \mathrm{e}-10)$, indicating it as a risk factor for lung cancer. Multivariate analysis value showed that low expression of CLEC3B may be an independent risk factor for disease-free survival in lung cancer patients $(H R=0.655,95 \% \mathrm{Cl} 0.430-0.996, \mathrm{Cox} P=0.048)$. In addition, we also investigated the potential role of CLEC3B in tumor-immune interactions and found that CLEC3B might be associated with the immune infiltration and immune activation of lung cancer, especially in squamous cell carcinoma.

\footnotetext{
*Correspondence: huangxx@whu.edu.cn

${ }^{\dagger}$ Jiaxing Sun and Tian Xie contributed equally to this work

${ }^{1}$ Department of Blood Transfusion, Zhongnan Hospital of Wuhan University, Wuhan, China

Full list of author information is available at the end of the article
}

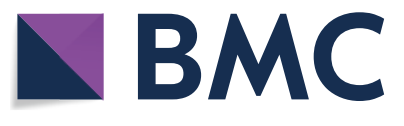

(c) The Author(s) 2020. This article is licensed under a Creative Commons Attribution 4.0 International License, which permits use, sharing, adaptation, distribution and reproduction in any medium or format, as long as you give appropriate credit to the original author(s) and the source, provide a link to the Creative Commons licence, and indicate if changes were made. The images or other third party material in this article are included in the article's Creative Commons licence, unless indicated otherwise in a credit line to the material. If material is not included in the article's Creative Commons licence and your intended use is not permitted by statutory regulation or exceeds the permitted use, you will need to obtain permission directly from the copyright holder. To view a copy of this licence, visit http://creativeco mmons.org/licenses/by/4.0/. The Creative Commons Public Domain Dedication waiver (http://creativecommons.org/publicdomain/ zero/1.0/) applies to the data made available in this article, unless otherwise stated in a credit line to the data. 
Conclusions: Our findings indicate that CLEC3B expression is downregulated in lung cancer and reveal the diagnostic and prognostic potential of CLEC3B in lung cancer and its potential as an immune-related therapeutic target in lung cancer.

Keywords: CLEC3B, Lung cancer, Prognosis, Diagnosis, Immune infiltration

\section{Background}

Lung cancer, including both small-cell and non-small-cell types, is the second most common cancer in both men and women and by far the leading cause of cancer-related death worldwide [1]. Due to the high percentage of lung cancer patients diagnosed at locally advanced or extensive metastatic stages, the prognosis in the majority of patients at the time of diagnosis is still poor [2,3]. Lung cancer patients diagnosed in an early stage and treated by surgery and radiotherapy showed better outcomes. However, with current diagnostic methods, such as computed tomography and positron emission tomography, there are still approximately $40 \%$ of lung cancer patients are diagnosed with distant metastasis [4]. Therefore, identifying effective biomarkers for early diagnosis and prognostication is important for reducing the mortality rate of lung cancer patients.

Increasing evidence has shown that the interaction between cancer cells and the tumor microenvironment, specifically the immune microenvironment, is also believed to be a key factor and showed to be involved in the tumor progression and therapy [5]. In recent years, $T$ cell checkpoint inhibitors have greatly improved therapeutic efficacy in multiple cancers. Inhibitors of programmed cell death receptor-1 (PD-1) and its ligand (PD-L1) have shown promising antitumor effects in various cancers, including non-small-cell lung cancer (NSCLC) [6]. In addition, there is accumulating evidence that tumor-infiltrating immune cells affect the prognosis and efficacy of chemotherapy and immunotherapy [7]. Therefore, elucidating the immunophenotypes of tumorimmune interactions and identifying novel immunerelated therapeutic targets in lung cancer are of particular importance.

C-type lectin domain family 3 member B (CLEC3B) encodes tetranectin, a plasminogen kringle-4-binding protein that is located in cell plasma, extracellular matrix and exosomes $[8,9]$. Tetranectin plays a role in extracellular proteolysis by inducing plasminogen activation, which is associated with tumor invasion and metastasis $[8,10-13]$. Moreover, CLEC3B has been reported in multiple cancers, including hepatocellular carcinoma, ovarian cancer, and oral squamous cell carcinoma, but a large number of in-depth studies are still needed to elucidate the molecular mechanism and specific function of CLEC3B in cancer progression [8, 14-19]. So far, research on CLEC3B has been very limited. Dai W. et al. reported that downregulation of exosomal CLEC3B in hepatocellular carcinoma promotes metastasis and angiogenesis via AMP-activated protein kinase and vascular endothelial growth factor signals [8]. Liu J et al. reported that CLEC3B has an anti-proliferation function mediated by the mitogen-activated protein kinase pathway in clear cell renal cell carcinoma [15]. To our knowledge, the relationship between CLEC3B and tumor immunity and its function in lung cancer has not been reported. We hypothesize that CLEC3B may serve as a potential diagnostic and prognostic biomarker and novel immunerelated therapeutic target for lung cancer.

In this study, we used publicly available cancer databases to evaluate the prognostic and predictive role of CLEC3B expression, and to determine its correlation with the immune microenvironment phenotype.

\section{Materials and methods}

In this study, we analyzed both SCLC and NSCLC.

\section{Publicly-available databases analysis}

The Oncomine database was accessed to analyze CLEC3B mRNA expression in lung cancer. In this study, a $p$ value of 0.0001 , fold change of 2 and top $10 \%$ gene rank was set as the threshold. Eleven Oncomine datasets containing 1205 lung cancer samples were chosen to analyze the expression of CLEC3B in cancer vs noncancer tissues (Additional file 1: Table S1). Several datasets were obtained from the Gene Expression Omnibus (GEO) database to analyze the expression of CLEC3B between lung cancer and noncancer tissues. Gene expression profiles for adenocarcinoma (ADC) and squamous cell cancer (SCC) patients were obtained from the TCGA database (https://portal.gdc.cancer.gov/).

Estimation of Stromal and Immune cells in MAlignant Tumor tissues using Expression data (ESTIMATE) is a method that uses gene expression signatures to infer the fraction of stromal and immune cells in tumor samples [20]. Based on the gene expression profiles downloaded from the TCGA database, immune scores were calculated by the ESTIMATE algorithm using the R-package "estimate". According to the rank of immune scores, we divided the ADC and SCC cases into two groups by the median value. The group with higher immune scores was 
defined as the high score group, and the other group was defined as the low score group.

Tumor immune estimation resource (TIMER) is a web server for comprehensive analysis of tumor-infiltrating immune cells (https://cistrome.shinyapps.io/timer/) [21]. The abundances of six immune infiltrates (B cells, CD4+ $\mathrm{T}$ cells, CD8+ $\mathrm{T}$ cells, neutrophils, macrophages and dendritic cells) can be estimated from gene expression profiles by a statistical method, which is validated using pathological estimations. In addition, the "correlation" module can create scatterplots illustrating the expression of a pair of genes in a particular cancer type and also generates the Spearman correlation and estimated statistical significance, which can be adjusted by tumor purity (the proportion of cancer cells in the admixture) or age. We used this module to explore the correlations between CLEC3B expression and gene markers of immune infiltrating cells in ADC and SCC.

\section{CDNA chip and real-time PCR}

The cDNA chip (cDNA-HLugC030PT01, Xinchao, Shanghai, China) comprised 15 pairs of lung tumor and adjacent nontumor samples from 8 ADC patients and 7 SCC patients (Additional file 2: Table S2). The mRNA expression of CLEC3B was detected by real-time PCR, and $\beta$-actin acted as the internal control gene. PCR amplification was performed with ChamQ SYBR qPCR Master Mix (Q311-02, Vazyme, Nanjing, China) using the QuantStudio 6 Flex Real-Time PCR System (Thermo Fisher Scientific, Waltham, MA, USA) and the PCR parameters was provided in Additional file 3: the supplementary methods. The expression fold-changes were analyzed by the $2^{-\Delta \Delta \mathrm{Ct}}$ relative quantitative methods. The real-time PCR primer sequences were as follows:

$\beta$-actin forward: $5^{\prime}$-GAAGAGCTACGAGCTGCC TGA-3', reverse: $5^{\prime}$-CAGACAGCACTGTGTTGGCG-3'; CLEC3B forward: 5'-CCCAGACGAAGACCTTCC AC-3', reverse: 5'-CGCAGGTACTCATACAGGGC-3'.

\section{Lung cancer tissue microarray}

A lung cancer tissue microarray LAC-1403 was purchased from Servicebio Technology Co (Wuhan, China), including 34 pairs of lung tumor and peritumor tissues. The clinicopathologic characteristics of the patients are listed in Additional file 4: Table S3. The protein expression of CLEC3B was detected by immunohistochemistry, and the rabbit monoclonal anti-tetranectin (encoded by CLEC3B) antibody was purchased from Abcam (Cambridge, UK; ab108999). The protocol of immunohistochemistry was provided in Additional file 3: the supplementary methods. The histochemistry score (H-SCORE) was calculated out to assess the immunohistochemical results. H-SCORE $=$ (percentage of cells of weak intensity $\times 1)+($ percentage of cells of moderate intensity $\times 2)+($ percentage of cells of strong intensity $\times 3$ ). The percentage of stained area and intensity of stained cells were scored as 0 , negative; $1+$, weak; $2+$, moderate; $3+$, strong.

\section{Gene set enrichment analysis}

Gene set enrichment analysis (GSEA) is a computational method that determines whether a predefined set of genes has statistically significant, concordant differences between two biological states [22]. TCGA datasets of ADC and SCC with a functional gene set file (c5.all.v5.1) gene set were analyzed by GSEA to obtain biological processes enriched by CLEC3B. The samples were divided into a high CLEC3B expression group (top 50\%) and a low CLEC3B expression group (bottom $50 \%$ ). Gene sets with nominal $\mathrm{p}$-value $<0.05$ and $\mathrm{FDR}<0.25$ were considered statistically significant.

\section{Statistical analysis}

SPSS version (v. 21.0) and GraphPad Prism (v. 8.0) were used for statistical analysis and generating figures. Paired $\mathrm{t}$-test, unpaired $\mathrm{t}$-test and one-way ANOVA followed by Dunnett's test were used to compare the expression of CLEC3B in different groups. A Chi-square test was performed to analyze the correlation of CLEC3B expression and clinicopathological factors. The diagnostic value of CLEC3B in lung cancer was revealed by receiver operating characteristic (ROC) curves. The Kaplan-Meier Plotter (http://www.kmplot.com) was used to evaluate the prognostic value of CLEC3B in lung cancer [23]. According to the automatically selected best cutoff of CLEC3B expression, the patient samples were divided into a high expression group and a low expression group. The overall survival (OS) and progression-free survival (PFS) of lung cancer patients were evaluated, together with the log-rank P-values and hazard ratio (HR) with 95\% confidence intervals (CIs). Kaplan-Meier survival analysis of the GEO database (GSE30219 and GSE31210) was used to investigate the prognostic significance of CLEC3B, and the log-rank P-value was calculated. A Cox proportional hazards regression model was applied for the univariate and multivariate analyses of survival. The factors with prognostic significance in the univariate analysis were included in the subsequent multivariate analysis. p-values $<0.05$ were considered statistically significant.

\section{Results}

CLEC3B is downregulated in lung cancer and closely correlated with clinicopathological features

To examine the expression of CLEC3B in lung cancer, we assessed the published data for cancer and normal tissues from the GEO and TCGA databases. The results showed 
a significant downregulation of CLEC3B in several histological subtypes $(\mathrm{p}<0.001)$, including ADC, SCC, largecell carcinoma (LCC), large-cell neuroendocrine tumor (LCNE) and small-cell lung cancer (SCLC) compared with noncancerous lung tissues in GSE30219 (Fig. 1a). Furthermore, CLEC3B was uniformly downregulated in ADC, SCC, LCC of GSE19188 (Additional file 5: Figure S1a) and 17 analyses of Oncomine (Additional file 5: Figure S1b). Consistently, comparison of CLEC3B gene expression across the RNA-seq data from TCGA demonstrated the downregulation of CLEC3B in both ADC and SCC (Fig. 1b, c). Data from cancer and matched adjacent nontumor tissues of ADC and SCC patients in the TCGA further corroborated these results (Fig. 1d, e).

To further validate these results, the cDNA chip of lung cancer clinical samples was purchased and real-time PCR was carried out to assess CLEC3B mRNA expression. As expected, in comparison with matched adjacent nontumor tissues, a significant downregulation of CLEC3B was revealed in lung cancer tissues (Fig. 1f, g) and CLEC3B expression was downregulated in both $\mathrm{ADC}$ and $\mathrm{SCC}$ samples (Fig. 1h, i). In addition, the protein expression of CLEC3B was investigated by IHC staining using a tissue microarray, which also showed that CLEC3B had lower expression in tumor tissues than peritumor tissues (Fig. 2a, b). A paired t-test of $\mathrm{H}$-scores revealed that the downregulation of CLEC3B in lung cancer was significant $(\mathrm{P}<0.001)$ (Fig. 2c). The difference in ADC and SCC H-score was also significant (Fig. 2d, e).

To identify the correlation between CLEC3B expression and clinicopathological features, GSE30219 and GSE31210 were analyzed. We found that CLEC3B downregulation was closely associated with $\mathrm{T}$ stage $(\mathrm{p}<0.001)$, $\mathrm{N}$ stage $(\mathrm{p}<0.001)$, pathological stage $(\mathrm{p}<0.001)$, and smoking $(\mathrm{p}<0.001)$ (Tables 1,2$)$.

\section{CLEC3B has high diagnostic value in lung cancer}

The GEO and TCGA datasets were used to evaluate the diagnostic potential of CLEC3B in lung cancer. The ROC analysis of TCGA-ADC revealed significant diagnostic accuracy with AUC $=0.993$ (95\% CI 0.987-0.999), sensitivity $=97.6 \%$ (95\% CI 95.8-98.6\%), and specificity $=98.2 \%$ (95\% CI 90.2-99.9\%) (Fig. 3a); the analysis of TCGA-SCC also showed accuracy with AUC $=0.998$ $(95 \%$ CI $0.996-1.00)$, sensitivity $=97.0 \%$ (95\% CI $95.1-$ 98.2\%), and specificity $=100 \% \quad(95 \%$ CI $92.7-100 \%)$ (Fig. 3b). As shown in Fig. 3c, CLEC3B also showed high diagnostic accuracy in GSE30219 with AUC $=0.982(95 \%$ CI $0.952-1.00)$, sensitivity $=98.3 \%$ (95\% CI 96.1-99.3\%), and specificity $=92.9 \%$ (95\% CI $68.5-99.6 \%$ ). In addition, based on the clinical tissue samples H-SCORE mentioned above, the AUC value for the ability of CLEC3B to distinguish lung cancer tissue from nontumor tissue was 0.880 (95\% CI $0.795-0.964)$, with a sensitivity of $91.2 \%$ (95\% CI $77.0-96.9 \%)$ and a specificity of $76.5 \%(95 \%$ CI

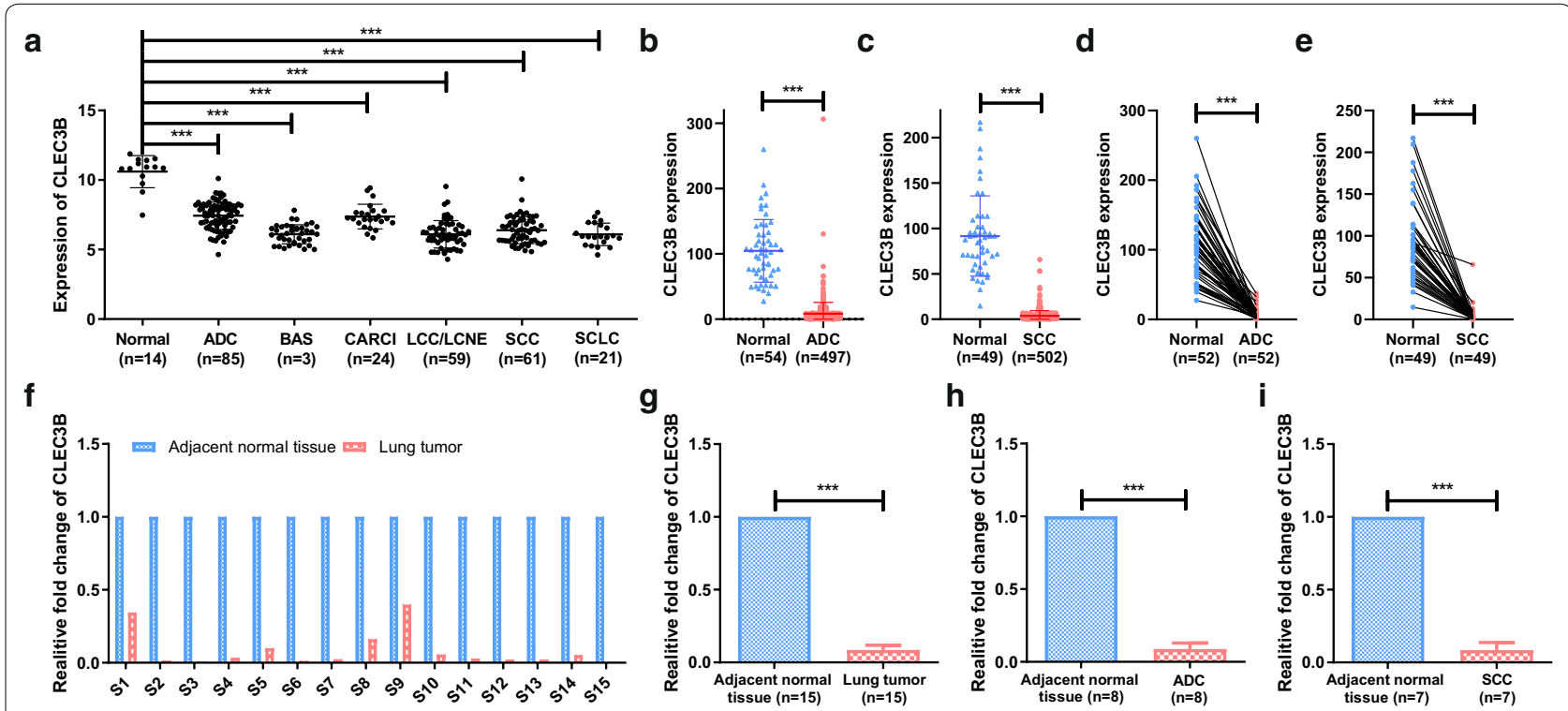

Fig. 1 The expression of CLEC3B was downregulated in lung cancer. a CLEC3B expression in normal lung tissue and different histological subtypes of lung cancer in GSE30219. b, c CLEC3B expression in ADC and SCC vs normal lung in the TCGA dataset. d, e Expression levels of CLEC3B in paired ADC and SCC samples in the TCGA dataset. $\mathbf{f}-\mathbf{i}$ Analysis of CLEC3B expression in 15 paired lung cancer specimens through real-time PCR. ADC, adenocarcinoma; BAS, basaloid; CARCI, carcinoid tumor; LCC, large-cell carcinoma; LCNE, large-cell neuroendocrine tumor; SCC, squamous cell carcinoma; SCLC, small-cell lung cancer. ${ }^{* *} \mathrm{p}<0.001$ 

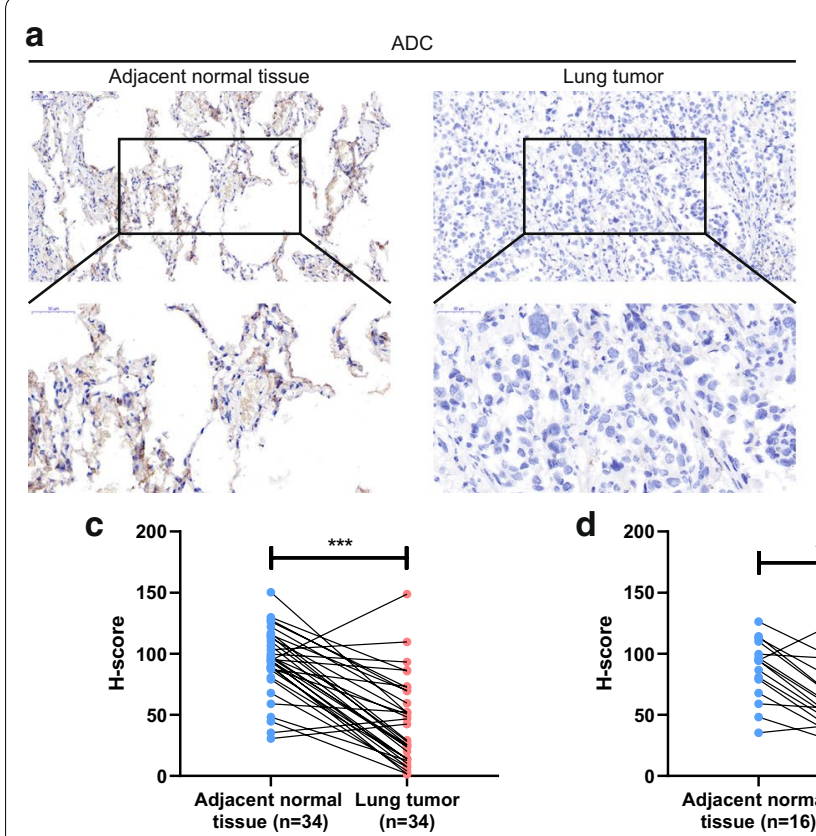
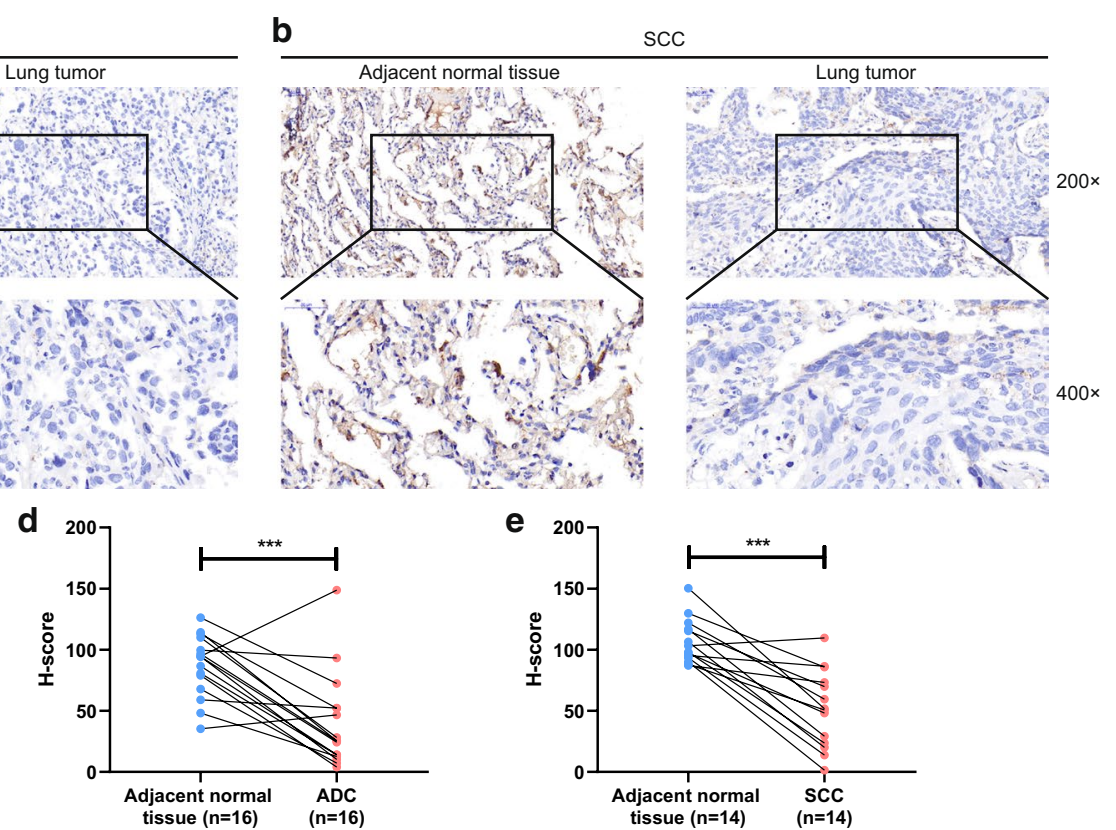

Fig. 2 Immunohistochemistry detection of CLEC3B in lung cancer and normal tissues. $\mathbf{a}$, $\mathbf{b}$ Representative images of immunohistochemistry staining (magnification, $\times 200, \times 400$ ) of ADC and SCC patients (the H-scores were 3.916 and 78.929 for image A; 20.068 and 106.444 for image B). c-e H-scores of clinical tumor and peritumor tissues for lung cancer samples. ADC, adenocarcinoma; SCC, squamous cell carcinoma; $\mathrm{H}$-score, histochemistry score. ${ }^{* * *} \mathrm{p}<0.001$

Table 1 Correlation between CLEC3B expression and the clinicopathological features of lung cancer patients in GSE30219

\begin{tabular}{|c|c|c|c|c|c|}
\hline \multirow[t]{2}{*}{ Characteristics } & \multirow[t]{2}{*}{$\begin{array}{l}\text { No. } \\
\text { of patients }\end{array}$} & \multicolumn{2}{|c|}{$\begin{array}{l}\text { CLEC3B } \\
\text { expression }\end{array}$} & \multirow[t]{2}{*}{$\begin{array}{l}\text { Chi square } \\
\text { value }\end{array}$} & \multirow[t]{2}{*}{$p$-value } \\
\hline & & Low & High & & \\
\hline Age (years) & & & & 0.434 & 0.510 \\
\hline$\leq 55$ & 79 & 42 & 37 & & \\
\hline$>55$ & 213 & 104 & 109 & & \\
\hline Gender & & & & 7.742 & 0.005 \\
\hline Male & 250 & 133 & 117 & & \\
\hline Female & 43 & 13 & 30 & & \\
\hline Tstage & & & & 45.647 & 0.000 \\
\hline 1 & 166 & 58 & 108 & & \\
\hline 2 & 69 & 40 & 29 & & \\
\hline 3 & 31 & 25 & 6 & & \\
\hline 4 & 21 & 20 & 1 & & \\
\hline N stage & & & & 44.990 & 0.000 \\
\hline 0 & 198 & 72 & 126 & & \\
\hline 1 & 53 & 42 & 11 & & \\
\hline $2-3$ & 40 & 31 & 9 & & \\
\hline M stage & & & & 0.514 & 0.473 \\
\hline 0 & 282 & 140 & 142 & & \\
\hline 1 & 8 & 5 & 3 & & \\
\hline
\end{tabular}

Table 2 Correlation between CLEC3B expression and the clinicopathological features of lung cancer patients in GSE31210

\begin{tabular}{|c|c|c|c|c|c|}
\hline \multirow[t]{2}{*}{ Characteristics } & \multirow[t]{2}{*}{$\begin{array}{l}\text { No. } \\
\text { of patients }\end{array}$} & \multicolumn{2}{|c|}{$\begin{array}{l}\text { CLEC3B } \\
\text { expression }\end{array}$} & \multirow[t]{2}{*}{$\begin{array}{l}\text { Chi square } \\
\text { value }\end{array}$} & \multirow[t]{2}{*}{ p-value } \\
\hline & & Low & High & & \\
\hline \multicolumn{2}{|l|}{ Age (years) } & & & 0.091 & 0.763 \\
\hline$\leq 55$ & 60 & 31 & 29 & & \\
\hline$>55$ & 166 & 82 & 84 & & \\
\hline \multicolumn{2}{|l|}{ Gender } & & & 3.006 & 0.083 \\
\hline Male & 121 & 54 & 67 & & \\
\hline Female & 105 & 59 & 46 & & \\
\hline \multicolumn{2}{|l|}{ Smoke } & & & 12.907 & 0.000 \\
\hline Non & 115 & 44 & 71 & & \\
\hline Yes & 111 & 69 & 42 & & \\
\hline \multicolumn{2}{|c|}{ Pathological stage } & & & 18.430 & 0.000 \\
\hline IA & 114 & 46 & 68 & & \\
\hline $\mathrm{IB}$ & 54 & 24 & 30 & & \\
\hline$\|$ & 58 & 43 & 15 & & \\
\hline \multicolumn{2}{|l|}{ P stage i or ii } & & & 18.184 & 0.000 \\
\hline I & 168 & 70 & 98 & & \\
\hline$\|$ & 58 & 43 & 15 & & \\
\hline
\end{tabular}


a

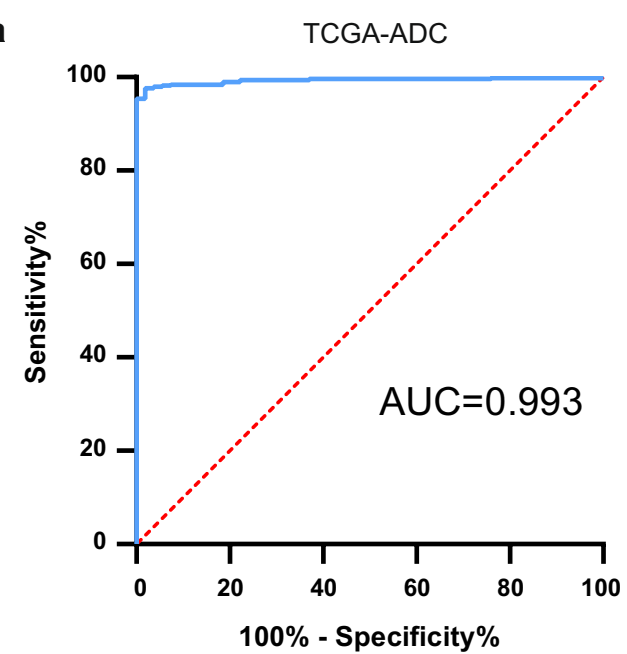

C

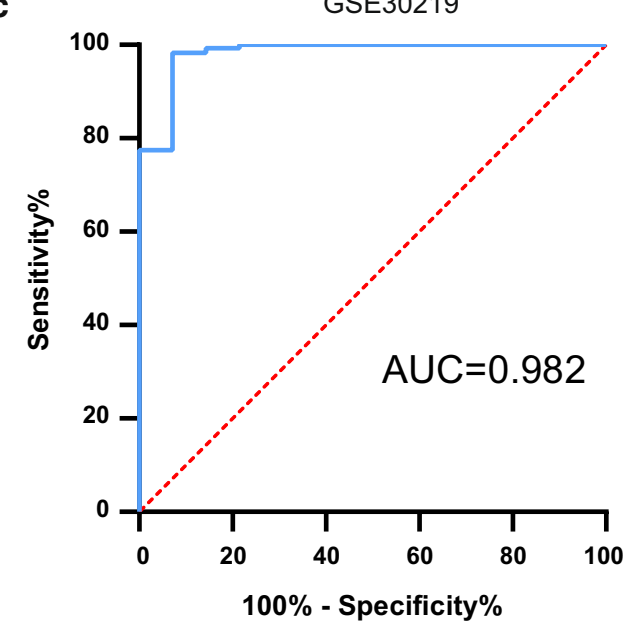

e

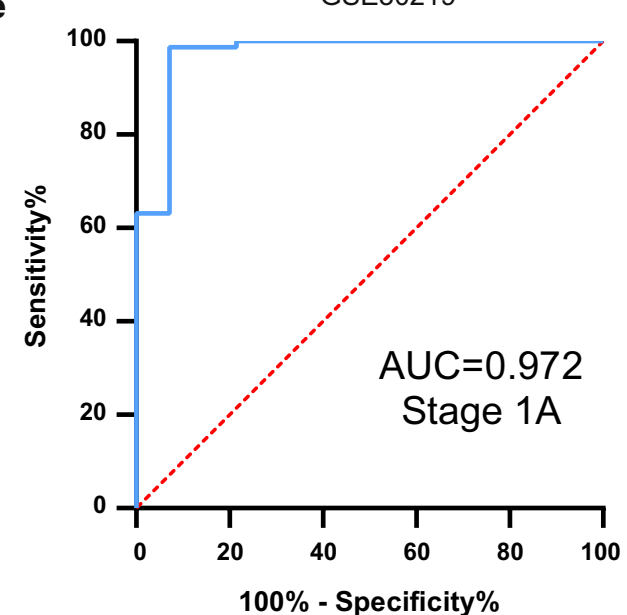

b

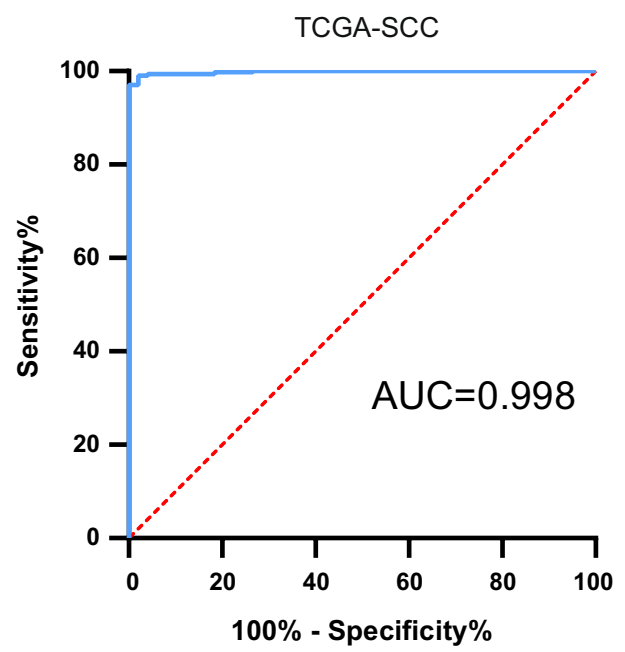

d

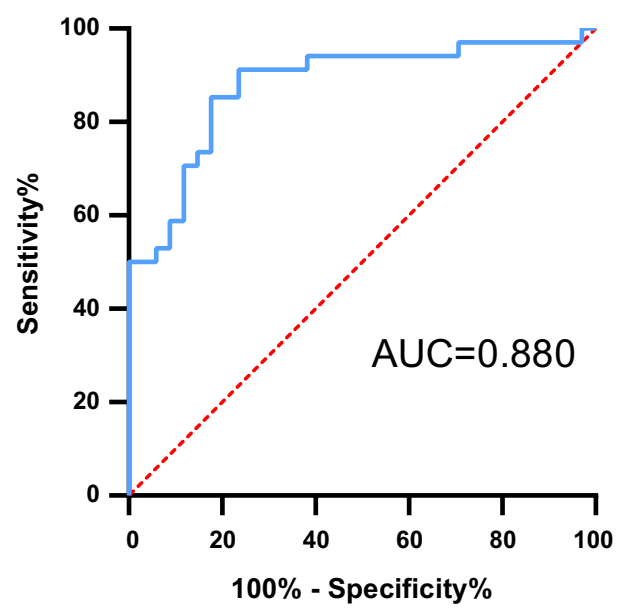

f

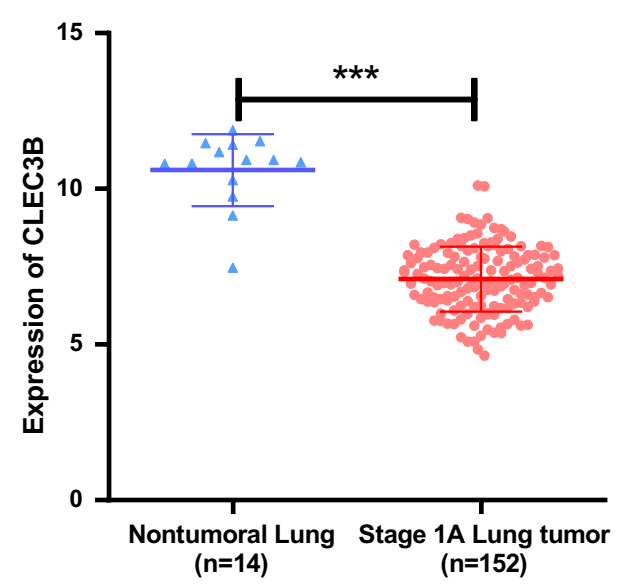

Fig. 3 Diagnostic value of CLEC3B in lung cancer. a, b ROC curves for ADC patients and SCC patients in TCGA datasets. $\mathbf{c}$ ROC curve for all lung cancer patients in GSE30219. d ROC curve for lung cancer patients of tissue microarray LAC-1403. e ROC curve for stage IA lung cancer patients in GSE30219. f CLEC3B expression in normal lung and stage IA lung cancer in GSE30219. ROC curve, receiver operating characteristic curve; AUC, area under the receiver operating characteristic curve; ADC, adenocarcinoma; SCC, squamous cell carcinoma. ${ }^{* *} p<0.001$ 
60.0-87.6\%) (Fig. 3d). Furthermore, we separated the stage IA patients and analyzed the diagnostic value of CLEC3B in GSE30219 with results of AUC $=0.972$ (95\% CI $0.922-1.00)$, sensitivity $=98.7 \%$ (95\% CI 95.3-99.8\%), and specificity $=92.9 \%$ (95\% CI 68.5-99.6\%) (Fig. 3e). CLEC3B was significantly downregulated in stage IA lung cancer patients (Fig. 3f). These results revealed that CLEC3B had a high diagnostic performance in differentiating lung cancer patients from normal individuals, even for the early stages of lung cancer.

\section{Decreased CLEC3B expression is a predictor of poor prognosis in lung cancer}

Using the Kaplan-Meier Plotter database and GEO datasets, we investigated the prognostic value of CLEC3B. Patients were split according to the automatically selected best cutoff value of CLEC3B expression. The Kaplan-Meier curve and log-rank test analyses revealed that among all patients, those with lower expression of CLEC3B had significantly poorer OS than those with high expression $(\mathrm{HR}=0.66,95 \% \mathrm{CI} 0.58-0.75$, $\mathrm{p}=2.1 \mathrm{e}-10$ ) (Fig. 4a); this was also true for ADC patients $(\mathrm{HR}=0.76,95 \%$ CI 0.60-0.97, $\mathrm{p}=0.025)$ (Fig. 4b) and SCC patients $(\mathrm{HR}=0.70,95 \%$ CI $0.53-0.91, \mathrm{p}=0.0076)$ (Fig. 4c). In addition, the results showed that low expression of CLEC3B predicted poorer PFS than high expression in all lung cancer patients $(\mathrm{HR}=0.60,95 \% \mathrm{CI}$ $0.49-0.74, \mathrm{p}=8.3 \mathrm{e}-07)$, ADC patients $(\mathrm{HR}=0.50,95 \%$ CI $0.36-0.69, \mathrm{p}=1.6 \mathrm{e}-05)$ and SCC patients $(\mathrm{HR}=0.40$, 95\% CI 0.23-0.67, p=0.00038) (Fig. 4d-f).

To better understand the effect of low expression of CLEC3B on survival, the Kaplan-Meier plotter database was accessed to analyze the correlation between CLEC3B expression and clinical characteristics of patients. Downregulation of CLEC3B was linked to worse OS and PFS in stage 1 to 2 , stage T1 to T2 and stage N0 to N1 lung cancer patients $(\mathrm{p}<0.05)$. In addition, the low expression of CLEC3B predicted

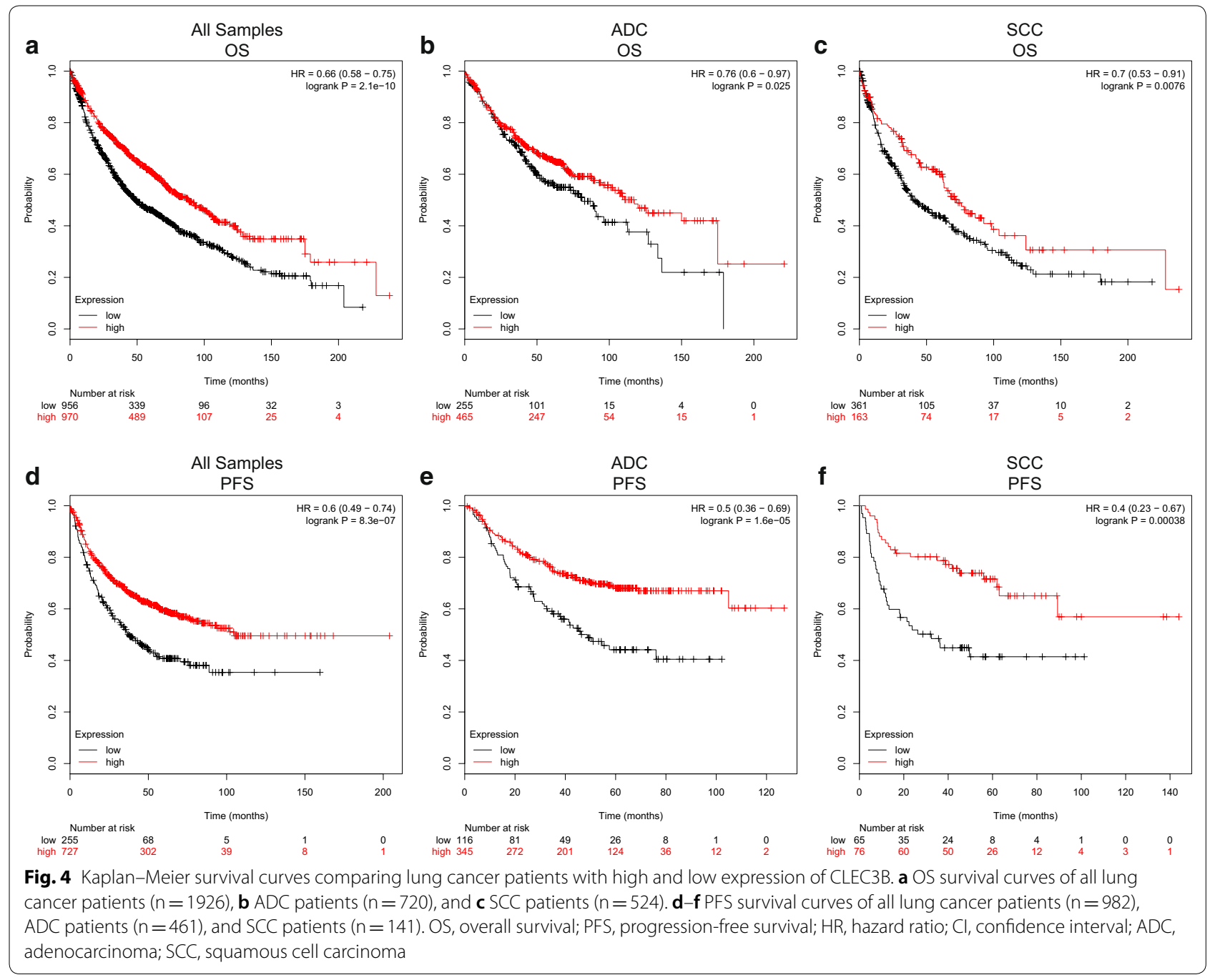


Table 3 Correlation of CLEC3B expression and prognosis in lung cancer with clinicopathological factors by Kaplan-Meier plotter

\begin{tabular}{|c|c|c|c|c|c|c|}
\hline \multirow{2}{*}{$\begin{array}{l}\text { Clinicopathological } \\
\text { characteristics }\end{array}$} & \multicolumn{3}{|c|}{ Overall survival $(n=1928)$} & \multicolumn{3}{|c|}{ Progression-free survival $(n=982)$} \\
\hline & $N$ & $\mathrm{HR}(95 \% \mathrm{Cl})$ & p-value & $N$ & HR $(95 \% \mathrm{Cl})$ & p-value \\
\hline \multicolumn{7}{|l|}{ Sex } \\
\hline Female & 715 & $0.64(0.5-0.81)$ & 0.00022 & 468 & $0.59(0.44-0.80)$ & 0.00051 \\
\hline Male & 1100 & $0.69(0.59-0.81)$ & $5.9 e-06$ & 514 & $0.62(0.48-0.80)$ & 0.00026 \\
\hline \multicolumn{7}{|l|}{ Stage } \\
\hline 1 & 577 & $0.58(0.44-0.76)$ & $5.85 e-05$ & 325 & $0.51(0.33-0.81)$ & 0.0033 \\
\hline 2 & 244 & $1.61(1.06-2.45)$ & 0.024 & 130 & $0.40(0.20-0.81)$ & 0.0089 \\
\hline 3 & 70 & $1.49(0.83-2.70)$ & 0.18 & 19 & na & na \\
\hline 4 & 4 & na & na & 0 & na & na \\
\hline \multicolumn{7}{|l|}{ T stage } \\
\hline 1 & 437 & $0.64(0.48-0.86)$ & 0.0024 & 177 & $0.49(0.29-0.84)$ & 0.008 \\
\hline 2 & 589 & $0.66(0.52-0.83)$ & 0.00044 & 351 & $0.50(0.34-0.74)$ & $4 e-04$ \\
\hline 3 & 81 & $1.69(1.03-2.78)$ & 0.037 & 21 & $0.65(0.24-1.80)$ & 0.41 \\
\hline 4 & 46 & $0.50(0.26-0.96)$ & 0.033 & 7 & na & na \\
\hline \multicolumn{7}{|l|}{ N stage } \\
\hline 0 & 781 & $0.69(0.56-0.86)$ & 0.00066 & 374 & $0.59(0.43-0.82)$ & 0.0013 \\
\hline 1 & 252 & $0.67(0.48-0.92)$ & 0.014 & 130 & $0.38(0.21-0.67)$ & 0.00051 \\
\hline 2 & 111 & $0.72(0.45-1.14)$ & 0.15 & 51 & $0.50(0.25-1.00)$ & 0.047 \\
\hline \multicolumn{7}{|l|}{ M stage } \\
\hline 0 & 681 & $0.61(0.49-0.75)$ & $2.3 e-06$ & 195 & $0.56(0.33-0.94)$ & 0.026 \\
\hline 1 & 10 & na & na & 0 & na & na \\
\hline \multicolumn{7}{|l|}{ Grade } \\
\hline 1 & 201 & $0.84(0.58-1.21)$ & 0.35 & 140 & $0.68(0.42-1.10)$ & 0.12 \\
\hline$\|$ & 310 & $0.63(0.45-0.87)$ & 0.0052 & 165 & $0.48(0.30-0.77)$ & 0.002 \\
\hline III & 77 & $0.47(0.24-0.91)$ & 0.022 & 51 & $1.47(0.64-3.35)$ & 0.36 \\
\hline \multicolumn{7}{|l|}{ Smoke } \\
\hline Ever & 820 & $0.76(0.62-0.93)$ & 0.0082 & 603 & $0.58(0.44-0.75)$ & $2.7 e-05$ \\
\hline Never & 205 & $0.41(0.23-0.72)$ & 0.0013 & 193 & $0.48(0.29-0.79)$ & 0.0032 \\
\hline
\end{tabular}

Values in italics indicate $p<0.05$

$\mathrm{Cl}$, confidence interval; $\mathrm{HR}$, hazard ratio; na, not applicable

poor OS and PFS in both smoking and nonsmoking patients $(\mathrm{p}<0.05)$ (Table 3$)$. Cox regressive models were performed to further evaluate the prognostic potential of CLEC3B expression. CLEC3B expression $(\mathrm{HR}=0.565,95 \%$ CI $0.423-0.753$, Cox $\mathrm{p}=0.000)$ was a significant predictor of OS in the univariate analysis (Table 4). The multivariate analysis value for diseasefree survival (DFS) was significant $(\mathrm{HR}=0.655,95 \% \mathrm{CI}$ 0.430-0.996, Cox $\mathrm{p}=0.048$ ) but not for OS (Table 5). Therefore, the lower expression of CLEC3B may be defined as an independent risk factor for DFS in lung cancer patients. Furthermore, low expression of CLEC3B, which is capable of predicting poor OS and DFS, was also validated in the GSE30219 (Additional file 6: Figure S2 a, b) and GSE30210 datasets (Additional file 6: Figure S2 c, d).

\section{CLEC3B expression is associated with immune infiltration} in lung cancer

Cancer patients diagnosed with the same histology types may have different immune infiltration levels, which could lead to diverse clinical outcomes [21, 24]. The increased number of tumor-infiltrating lymphocytes in primary tumor tissue relating to good prognosis has been reported in several cancers, including NSCLC [25, 26]. Therefore, the correlation of CLEC3B and immune infiltration levels was evaluated to reveal the possible 
Table 4 Univariate and multivariate analyses for lung cancer patients on overall survival in the GSE30219

\begin{tabular}{|c|c|c|c|c|}
\hline \multirow[t]{2}{*}{ Variable } & \multicolumn{2}{|l|}{ Univariate analysis } & \multicolumn{2}{|l|}{ Multivariate analysis } \\
\hline & HR (95\% Cl) & p-value & $\mathrm{HR}(95 \% \mathrm{Cl})$ & p-value \\
\hline Age ( $\leq 55$ vs $>55$ years) & $1.039(1.025-1.054)$ & 0.000 & $1.041(1.026-1.056)$ & 0.000 \\
\hline \multicolumn{5}{|l|}{ Gender } \\
\hline Female vs male & $0.573(0.360-0.910)$ & 0.018 & $0.670(0.419-1.071)$ & 0.094 \\
\hline \multicolumn{5}{|l|}{ Tstage } \\
\hline T1 vs T2 vs T3 vs T4 & $1.625(1.415-1.866)$ & 0.000 & $1.311(1.082-1.590)$ & 0.006 \\
\hline \multicolumn{5}{|l|}{ N stage } \\
\hline No vs N1 vs N2 vs N4 & $1.730(1.472-2.034)$ & 0.000 & $1.371(1.097-1.715)$ & 0.006 \\
\hline \multicolumn{5}{|l|}{ M stage } \\
\hline M0 vs M1 & $2.718(1.114-6.631)$ & 0.028 & $2.432(0.987-5.997)$ & 0.054 \\
\hline \multicolumn{5}{|l|}{ CLEC3B expression } \\
\hline High vs low & $0.565(0.423-0.753)$ & 0.000 & $0.789(0.577-1.077)$ & 0.136 \\
\hline
\end{tabular}

$\mathrm{Cl}$, confidence interval; $\mathrm{HR}$, hazard ratio

Table 5 Univariate and multivariate analyses for lung cancer patients on disease-free survival in the GSE30219

\begin{tabular}{|c|c|c|c|c|}
\hline \multirow[t]{2}{*}{ Variable } & \multicolumn{2}{|l|}{ Univariate analysis } & \multicolumn{2}{|l|}{ Multivariate analysis } \\
\hline & $\mathrm{HR}(95 \% \mathrm{Cl})$ & p-value & $\mathrm{HR}(95 \% \mathrm{Cl})$ & p-value \\
\hline Age ( $\leq 55$ vs $>55$ years) & 1.027 (1.009-1.045) & 0.003 & 1.029 (1.010-1.048) & 0.003 \\
\hline \multicolumn{5}{|l|}{ Gender } \\
\hline Female vs male & $0.746(0.433-1.285)$ & 0.290 & & \\
\hline \multicolumn{5}{|l|}{ T stage } \\
\hline T1 vs T2 vs T3 vs T4 & $1.882(1.587-2.232)$ & 0.000 & $1.309(1.027-1.670)$ & 0.030 \\
\hline \multicolumn{5}{|l|}{ N stage } \\
\hline N0 vs N1 vs N2 vs N4 & $2.618(1.791-2.624)$ & 0.000 & $1.652(1.259-2.169)$ & 0.000 \\
\hline \multicolumn{5}{|l|}{ M stage } \\
\hline M0 vs M1 & $3.837(1.408-10.456)$ & 0.009 & $3.951(1.428-10.933)$ & 0.008 \\
\hline \multicolumn{5}{|l|}{ CLEC3B expression } \\
\hline High vs low & $0.442(0.300-0.650)$ & 0.000 & $0.655(0.430-0.996)$ & 0.048 \\
\hline
\end{tabular}

$\mathrm{Cl}$, confidence interval; $\mathrm{HR}$, hazard ratio

mechanism by which CLEC3B affects the prognosis of lung cancer.

The immune scores of the patient samples were calculated by the ESTIMATE algorithm using the data from TCGA database to predict the presence of infiltrating immune cells in tumor tissues. According to the rank of immune scores, we divided the ADC and SCC cases into high and low score groups by the median value. The results showed that $C L E C 3 B$ was upregulated in the high immune score group of SCC, but there was no statistical significance in ADC, which indicated that CLEC3B might be involved in the immune infiltration of SCC (Fig. 5a, b).

To further validate the relationship between CLEC3B expression and immune infiltration of lung cancer, we used TIMER to evaluate the correlations of CLEC3B expression with tumor purity and infiltrating levels of immune cells. The results showed that CLEC3B expression was slightly correlated with ADC tumor purity but had a more significant correlation with tumor purity and immune infiltration levels of SCC. In ADC, the expression level of CLEC3B had no significant correlations with the infiltration of CD8+ T cells, CD4+ T cells, neutrophils and dendritic cells (DCs) (Fig. 5c-i). However, in SCC, the expression of CLEC3B was significantly positively correlated with the infiltration of B cells $(r=0.289$, $\mathrm{p}=1.47 \mathrm{e}-10), \mathrm{CD} 8+\mathrm{T}$ cells $(\mathrm{r}=0.232, \mathrm{p}=3.33 \mathrm{e}-07)$, $\mathrm{CD} 4+\mathrm{T}$ cells $(\mathrm{r}=0.24, \mathrm{p}=1.20 \mathrm{e}-07)$, macrophages $(\mathrm{r}=0.364, \quad \mathrm{p}=2.18 \mathrm{e}-16), \quad$ neutrophils $\quad(\mathrm{r}=0.146$, $\mathrm{p}=1.41 \mathrm{e}-03)$ and DCs $(\mathrm{r}=0.273, \quad \mathrm{p}=1.41 \mathrm{e}-09)$ 


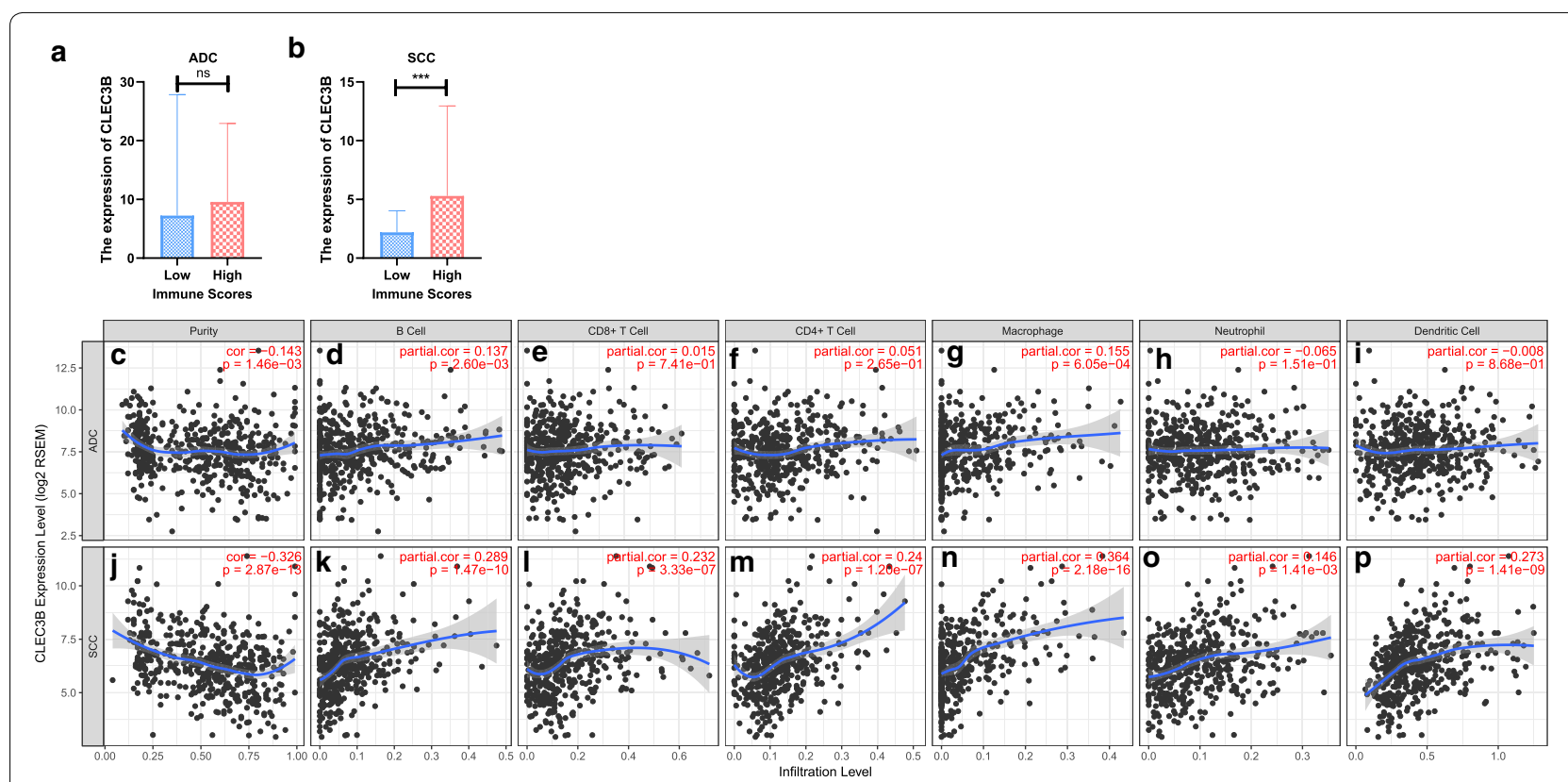

Fig. 5 Correlation of CLEC3B expression with immune infiltration level in ADC and SCC. $\mathbf{a}, \mathbf{b}$ Comparison of CLEC3B expression between the high and low immune score groups of ADC and SCC. $\mathbf{c}-\mathbf{p}$ CLEC3B is related to tumor purity and immune infiltration levels of ADC and SCC by TIMER analysis. ADC, adenocarcinoma; SCC, squamous cell carcinoma; ns, no significance. ${ }^{* * *} \mathrm{p}<0.001$

(Fig. 5j-p). These findings suggest that CLEC3B may play an important role in immune infiltration of SCC.

The correlations between CLEC3B and immune markers of immune cells (selected by investigating some relevant papers [27-31]) were analyzed in the TIMER database to explore the relationship between CLEC3B and immune infiltrating cells of ADC and SCC (Table 6). In SCC, CLEC3B expression was positively correlated with majority of gene markers of different functional $\mathrm{T}$ cells (CD8+ T, Th1, Th2, etc.), B cells, dendritic cells, neutrophils and natural killer cells after adjusting for purity, which was consistent with the results in Fig. 5. Moreover, CLEC3B was related to tumor-associated macrophage (TAM) infiltration, which exerts both antiand pro-tumor effects. However, CLEC3B expression only had a strong correlation with few markers for B cells, DCs, neutrophils, natural killer cells and Th1 cells in ADC. The results showed that the expression level of CLEC3B was significantly correlated with most immune markers of immune cells in SCC but only a few markers in ADC. These findings may provide an explanation for the difference in the prognostic value of CLEC3B in ADC and SCC.

\section{CLEC3B is involved in immune activation and proliferation inhibition in lung cancer}

GSEA was used to explore the mechanisms of CLEC3B in lung cancer. The TCGA data of ADC and SCC were divided into high (top 50\%) and low (bottom 50\%) CLEC3B expression groups according to the median expression of CLEC3B. TCGA data were analyzed with GMT file C5 (GO gene set). The top 20 enrichment results (nominal $\mathrm{p}$ value $<0.05$ and $\mathrm{FDR}<0.25$ ) are shown in Additional files 7, 8, 9, 10: Tables S4, S5, S6, S7. There were few enrichment results related to cancer progression in the CLEC3B high expression ADC, whereas in the CLEC3B high expression group of SCC, many gene sets related to immune activation were enriched, suggesting that CLEC3B may suppress the progression of SCC through immune activation, which is also consistent with the previous results (Fig. 6a-e). In addition, several cell cycle-related gene sets were enriched in the CLEC3B low expression group of $\mathrm{ADC}$ and $\mathrm{SCC}$, which suggests that CLEC3B may also be involved in the inhibition of cell proliferation in lung cancer (Fig. $6 \mathrm{f}-\mathrm{o}$ ).

\section{Discussion}

Lung cancer is the leading cause of cancer associated mortality. Cancer survival largely depends on the stage at diagnosis; however, $40-60 \%$ of lung cancer patients are not diagnosed until advanced stages [32]. In the present 
Table 6 Correlation analysis between CLEC3B and relate genes and markers of immune cells in TIMER

\begin{tabular}{|c|c|c|c|c|c|c|c|c|c|}
\hline \multirow[t]{3}{*}{ Description } & \multirow[t]{3}{*}{ Gene markers } & \multicolumn{4}{|l|}{$A D C$} & \multicolumn{4}{|l|}{ SCC } \\
\hline & & \multicolumn{2}{|l|}{ None } & \multicolumn{2}{|l|}{ Purity } & \multicolumn{2}{|l|}{ None } & \multicolumn{2}{|l|}{ Purity } \\
\hline & & Cor & $\mathbf{P}$ & Cor & $\mathbf{P}$ & Cor & $\mathbf{P}$ & Cor & $\mathbf{P}$ \\
\hline \multirow[t]{3}{*}{ CD8+T cell } & CD8A & 0.07 & 0.113 & 0.003 & 0.95 & 0.322 & $* * *$ & 0.238 & $* * *$ \\
\hline & CD8B & 0.08 & 0.071 & 0.035 & 0.438 & 0.276 & $* * *$ & 0.232 & $* * *$ \\
\hline & CD45 & 0.2 & $* * *$ & 0.126 & $* *$ & 0.447 & $* * *$ & 0.361 & $* * *$ \\
\hline \multirow[t]{3}{*}{ T cell (general) } & CD3D & 0.138 & $*$ & 0.066 & 0.144 & 0.382 & $* * *$ & 0.279 & $* * *$ \\
\hline & CD3E & 0.168 & $* *$ & 0.101 & 0.024 & 0.397 & $* * *$ & 0.294 & $* * *$ \\
\hline & CD2 & 0.155 & $* *$ & 0.083 & 0.067 & 0.382 & $* * *$ & 0.282 & $* * *$ \\
\hline \multirow[t]{4}{*}{ B cell } & CD19 & 0.194 & $* * *$ & 0.145 & $*$ & 0.414 & $* * *$ & 0.316 & $* * *$ \\
\hline & CD79A & 0.154 & $* *$ & 0.105 & 0.020 & 0.385 & $* * *$ & 0.279 & $* * *$ \\
\hline & CD27 & 0.148 & $* * *$ & 0.091 & $*$ & 0.384 & $* * *$ & 0.289 & $* * *$ \\
\hline & CD20 & 0.293 & $* * *$ & 0.249 & $* * *$ & 0.481 & $* * *$ & 0.415 & $* * *$ \\
\hline \multirow[t]{2}{*}{ Monocyte } & CD14 & 0.065 & 0.139 & 0 & 0.994 & 0.391 & $* * *$ & 0.281 & $* * *$ \\
\hline & CD115 (CSF1R) & 0.11 & 0.012 & 0.04 & 0.373 & 0.449 & $* * *$ & 0.357 & $* * *$ \\
\hline \multirow[t]{3}{*}{ TAM } & CCL2 & 0.03 & 0.5 & -0.036 & 0.419 & 0.31 & $* * *$ & 0.229 & $* * *$ \\
\hline & CD68 & 0.165 & $* *$ & 0.11 & 0.015 & 0.372 & $* * *$ & 0.27 & $* * *$ \\
\hline & IL10 & 0.198 & $* * *$ & 0.132 & $*$ & 0.41 & $* * *$ & 0.335 & $* * *$ \\
\hline \multirow[t]{5}{*}{ M1 Macrophage } & INOS (NOS2) & 0.236 & $* * *$ & 0.23 & $* * *$ & 0.11 & 0.014 & 0.116 & 0.011 \\
\hline & CD80 & 0.101 & $*$ & 0.021 & 0.643 & 0.302 & $* * *$ & 0.217 & $* * *$ \\
\hline & IRF5 & 0.037 & 0.4 & -0.021 & 0.635 & 0.152 & $* *$ & 0.116 & 0.011 \\
\hline & IL6 & 0.02 & 0.659 & -0.02 & 0.658 & 0.203 & $* * *$ & 0.154 & $* * *$ \\
\hline & CD64 (FCGR1A) & 0.012 & 0.792 & -0.069 & 0.127 & 0.404 & $* * *$ & 0.316 & $* * *$ \\
\hline \multirow[t]{4}{*}{ M2 Macrophage } & CD163 & 0.098 & 0.026 & 0.028 & 0.529 & 0.46 & $* * *$ & 0.373 & $* * *$ \\
\hline & CD206 & 0.306 & $* * *$ & 0.256 & $* * *$ & 0.456 & $* * *$ & 0.374 & $* * *$ \\
\hline & VSIG4 & 0.162 & $* *$ & 0.102 & 0.023 & 0.478 & $* * *$ & 0.4 & $* * *$ \\
\hline & MS4A4A & 0.233 & $* * *$ & 0.175 & $* * *$ & 0.49 & $* * *$ & 0.409 & $* * *$ \\
\hline \multirow[t]{3}{*}{ Neutrophils } & CD66b (CEACAM8) & 0.3 & $* * *$ & 0.29 & $* * *$ & 0.268 & $* * *$ & 0.255 & $* * *$ \\
\hline & CD11b (ITGAM) & 0.101 & 0.022 & 0.03 & 0.5 & 0.379 & $* * *$ & 0.27 & $* * *$ \\
\hline & CD15 & 0.017 & 0.706 & 0.001 & 0.976 & 0.146 & $* *$ & 0.123 & $* *$ \\
\hline \multirow[t]{6}{*}{ Natural killer cell } & KIR2DL1 & 0.213 & $* * *$ & 0.203 & $* * *$ & 0.174 & $* * *$ & 0.128 & $* * *$ \\
\hline & KIR2DL3 & 0.081 & 0.067 & 0.04 & 0.375 & 0.187 & $* * *$ & 0.145 & $*$ \\
\hline & KIR3DL1 & 0.142 & $*$ & 0.123 & $*$ & 0.272 & $* * *$ & 0.221 & $* * *$ \\
\hline & KIR3DL2 & 0.028 & 0.533 & -0.024 & 0.602 & 0.191 & $* * *$ & 0.135 & $*$ \\
\hline & CD56 & 0.208 & $* * *$ & 0.21 & $* * *$ & 0.211 & $* * *$ & 0.253 & $* * *$ \\
\hline & CD335 (NKp46) & 0.024 & 0.592 & -0.018 & 0.694 & 0.237 & $* * *$ & 0.183 & $* * *$ \\
\hline \multirow[t]{5}{*}{ Dendritic cell } & BDCA-1 (CD1C) & 0.415 & $* * *$ & 0.38 & $* * *$ & 0.524 & $* * *$ & 0.446 & $* * *$ \\
\hline & $\mathrm{BDCA}-3$ (CD141) & 0.4 & $* * *$ & 0.363 & $* * *$ & 0.519 & $* * *$ & 0.45 & $* * *$ \\
\hline & BDCA-4 (NRP1) & -0.017 & 0.699 & -0.042 & 0.357 & 0.257 & $* * *$ & 0.143 & $* *$ \\
\hline & CD123 & 0.347 & $* * *$ & 0.308 & $* * *$ & 0.535 & $* * *$ & 0.468 & $* * *$ \\
\hline & CD11c (ITGAX) & 0.137 & $*$ & 0.071 & 0.116 & 0.427 & $* * *$ & 0.319 & $* * *$ \\
\hline \multirow[t]{3}{*}{ Th1 } & T-bet (TBX21) & 0.134 & * & 0.064 & 0.159 & 0.365 & $* * *$ & 0.269 & $* * *$ \\
\hline & STAT4 & 0.138 & * & 0.078 & 0.084 & 0.431 & $* * *$ & 0.344 & $* * *$ \\
\hline & STAT1 & -0.204 & $* * *$ & -0.276 & $* * *$ & 0.026 & 0.56 & -0.059 & 0.199 \\
\hline \multirow[t]{3}{*}{ Th2 } & GATA3 & -0.033 & 0.457 & -0.114 & 0.012 & 0.203 & $* * *$ & 0.12 & $*$ \\
\hline & STAT6 & 0.242 & $* * *$ & 0.239 & $* * *$ & 0.123 & $*$ & 0.111 & 0.016 \\
\hline & IL13 & 0.148 & $* *$ & 0.104 & 0.021 & 0.235 & $* * *$ & 0.186 & $* * *$ \\
\hline Tfh & BCL6 & 0.058 & 0.189 & 0.068 & 0.134 & 0.075 & 0.092 & 0.102 & 0.025 \\
\hline & IL21 & -0.049 & 0.267 & -0.085 & 0.061 & 0.196 & $* * *$ & 0.122 & $*$ \\
\hline
\end{tabular}


Table 6 (continued)

\begin{tabular}{|c|c|c|c|c|c|c|c|c|c|}
\hline \multirow[t]{3}{*}{ Description } & \multirow[t]{3}{*}{ Gene markers } & \multicolumn{4}{|l|}{$A D C$} & \multicolumn{4}{|l|}{ SCC } \\
\hline & & \multicolumn{2}{|l|}{ None } & \multicolumn{2}{|l|}{ Purity } & \multicolumn{2}{|l|}{ None } & \multicolumn{2}{|l|}{ Purity } \\
\hline & & Cor & $\mathbf{P}$ & Cor & $\mathbf{P}$ & Cor & $\mathbf{P}$ & Cor & $\mathbf{P}$ \\
\hline \multirow[t]{3}{*}{ Th17 } & STAT3 & 0.048 & 0.275 & 0.051 & 0.255 & 0.072 & 0.109 & 0.006 & 0.89 \\
\hline & IL17A & 0.063 & 0.154 & 0.046 & 0.307 & 0.012 & 0.783 & -0.051 & 0.266 \\
\hline & RORyt & 0.202 & $* * *$ & 0.242 & $* * *$ & 0.517 & $* * *$ & 0.469 & $* * *$ \\
\hline \multirow[t]{4}{*}{ Treg } & FOXP3 & 0.003 & 0.947 & -0.081 & 0.072 & 0.281 & $* * *$ & 0.162 & $* *$ \\
\hline & CD25 & -0.039 & 0.371 & -0.117 & $* *$ & 0.293 & $* * *$ & 0.193 & $* * *$ \\
\hline & CCR8 & 0.015 & 0.729 & -0.064 & 0.155 & 0.263 & $* * *$ & 0.152 & $* *$ \\
\hline & STAT5B & 0.196 & $* * *$ & 0.18 & $* * *$ & 0.112 & 0.012 & 0.095 & 0.037 \\
\hline \multirow[t]{5}{*}{ T cell exhaustion } & PD-1 (PDCD1) & 0.01 & 0.816 & -0.065 & 0.149 & 0.346 & $* *$ & 0.249 & $* * *$ \\
\hline & CTLA4 & 0.046 & 0.293 & -0.046 & 0.31 & 0.306 & $* * *$ & 0.192 & $* * *$ \\
\hline & LAG3 & -0.085 & 0.054 & -0.154 & $* *$ & 0.17 & $* *$ & 0.078 & 0.087 \\
\hline & TIM-3 (HAVCR2) & 0.098 & 0.026 & 0.02 & 0.652 & 0.443 & $* * *$ & 0.356 & $* * *$ \\
\hline & GZMB & -0.089 & 0.045 & -0.16 & $* *$ & 0.222 & $* * *$ & 0.116 & 0.011 \\
\hline
\end{tabular}

ADC, adenocarcinoma; SCC, squamous cell carcinoma; None, correlation without adjustment; Purity, correlation adjusted by purity; TAM, tumor-associated macrophage; Th, T helper cell; Tfh, Follicular helper T cell; Treg, regulatory T cell; Cor, R value of Spearman's correlation

* $\mathrm{P}<0.01$; ${ }^{*} \mathrm{P}<0.001 ;{ }^{* *} \mathrm{P}<0.0001$

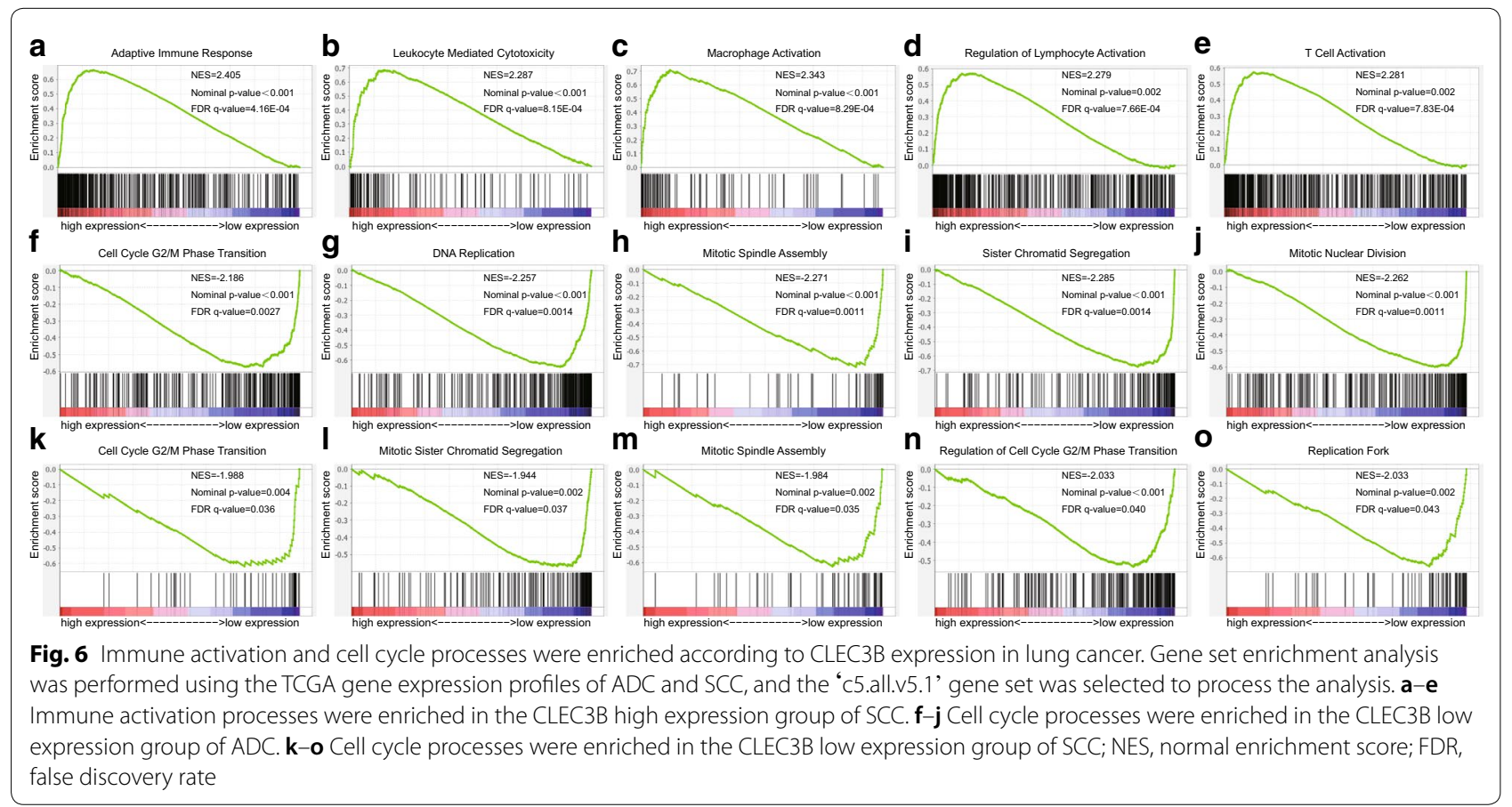

study, we observed a decrease in CLEC3B expression in lung cancer, which was associated with worse OS and DFS. Our results also suggested that CLEC3B is related to immune infiltration in lung cancer, which may be the mechanism by which CLEC3B affects prognosis. These results indicated that CLEC3B could serve as a potential biomarker for diagnosis and prognosis and could be considered as a novel immune-related therapeutic target.

CLEC3B, a member of the C-type lectin domain family, encodes the tetrameric protein tetranectin. Low expression of CLEC3B has been confirmed in several tumors. However, its expression level and function in lung cancer 
have not been reported previously. Database analysis and patient sample detection revealed that CLEC3B is significantly downregulated in various types of lung cancer. Furthermore, our results indicate that CLEC3B is significantly downregulated in stage IA and has great diagnostic value for lung cancer at an early stage, since the AUC value of CLEC3B for the diagnosis of stage IA lung cancer patients was approximately 1 , which indicates great significance. Thus, our results revealed that the expression of CLEC3B can distinguish lung cancer patients from healthy individuals with high sensitivity and specificity.

We found that the downregulation of CLEC3B was linked to worse PFS and OS. In addition, univariate and multivariate analyses indicated that the lower expression of CLEC3B may be defined as a risk factor that affects the OS and DFS of lung cancer patients. As such, we validated that CLEC3B has prognostic value in lung cancer. Moreover, the CLEC3B expression level was negatively correlated with TNM stage. Patients with a low level of CLEC3B were more likely to present with disease in a late TNM stage, suggesting that CLEC3B is a tumor suppressor gene of lung cancer. In oral squamous cell carcinoma, CLEC3B has been reported as a tumor suppressor [33].

Recent years have witnessed the rapid development of tumor immunotherapy. There has been increasing recognition of the role of the immune system in cancer development and progression [34, 35]. The exploration of the tumor microenvironment as a prognostic and diagnostic biomarker or therapy target is an area of active research [36]. Some studies have shown that immune cell infiltration has an influence on survival in lung cancer [37, 38]. Other significant findings of the present study are that CLEC3B plays a role in tumor-immune interactions and that CLEC3B expression is correlated with the immune infiltration level in lung cancer, especially in SCC. Our results revealed a most significantly positive correlation between CLEC3B expression and the level of B cells, CD8+ T cells, CD4+ T cells, macrophages and DCs infiltration in SCC.

In the NSCLC tumor microenvironment, the landscape of immune cell types is T cells, followed by B cells, macrophages, DCs and natural killer cells [28]. Dendritic cells are specialized antigen-presenting cells that play an important role in the activation of antitumor $\mathrm{T}$ lymphocytes $[39,40]$. The infiltration of $\mathrm{T}$ cells generally predicts a better clinical outcomes in patients [41]. In addition, the role of tumor-infiltrating B cells in the tumor microenvironment has attracted increasing attention. Most studies indicate that the infiltration of B cells in NSCLC is related to a favorable outcome [29]. In NSCLC patients who were not treated with PD-1/PD-L1 inhibitors, higher levels of $\mathrm{T}$ and $\mathrm{B}$ plasma cells were associated with better prognosis [42]. The results of GSEA further validated that CLEC3B may be involved in immune activation in SCC. In addition, our results showed that CLEC3B is related to macrophages in SCC. However, the role of macrophage infiltration and activation in lung cancer remains controversial [43]. Generally, TAMs play a pro-tumoral role; however, they could have the capacity to cooperate with $\mathrm{T}$ cells in anti-tumoral action under appropriate stimulation [44]. According to the latest report, high levels of M1, CD204+ M2, and macrophages infiltration are independent factors of favorable prognosis in stage I to III NSCLC patients [45]. Our results revealed that CLEC3B is capable of recruiting and regulating immune infiltrating cells in lung cancer. However, the precise role of CLEC3B in tumor immune microenvironment and tumor progression still needs further research exploration.

Taken together, our results indicate that CLEC3B may improve lung cancer patient prognosis through immune infiltration and immune activation. As to the different effects of CLEC3B on immune infiltration of SCC and $\mathrm{ADC}$, we think this may be due to the differences in their intrinsic immune microenvironments [46]. It is worth pointing out that the prognostic value of CLEC3B in SCC was more significant than that in ADC (Fig. 4), which may be due to the stronger correlation between CLEC3B expression and immune infiltration in SCC than in ADC. In addition, we also found that CLEC3B may be related to the inhibition of cell proliferation in lung cancer, which is consistent with a report in clear cell renal cell carcinoma $[15,33]$. The function of inhibiting cell proliferation is correlated with the prognosis of lung cancer patients [47]. Taken together, immune activation and proliferation inhibition induced by CLEC3B may be the two components of the gene's anticancer effect.

\section{Conclusion}

In conclusion, we found that CLEC3B is downregulated in lung cancer, and it may act as an early stage diagnostic marker in lung cancer patients. In addition, low expression of CLEC3B is associated with poor prognosis in lung cancer. Moreover, CLEC3B may promote tumor-induced immune response activation and immune infiltration in SCC and may inhibit the proliferation of lung cancer to play an anticancer role. Thus, we reported that CLEC3B is related to lung cancer and identified a possible potential diagnostic and prognostic biomarker and immunerelated therapeutic target for lung cancer. Further studies are needed to confirm these results and reveal the underlying mechanisms. 


\section{Supplementary information}

Supplementary information accompanies this paper at https://doi. org/10.1186/s12935-020-01183-1.

Additional file 1: Table S1. Comparison of CLEC3B expression across 17 analyses.

Additional file 2: Table S2. Clinical information of 15 lung cancer samples of cDNA chip (cDNA-HLugCO3OPT01).

Additional file 3. Supplementary methods.

Additional file 4: Table S3. Clinical information of 34 lung cancer samples of tissue microarray (LAC-1403).

Additional file 5: Figure S1. Downregulation of CLEC3B in lung cancer. (a) Analysis of CLEC3B expression in normal lung and different histological subtypes of lung cancer in GSE19188. (b) Analysis of CLEC3B expression across 17 analyses of Oncomine. ADC, adenocarcinoma; SCC, squamous cell carcinoma; $\mathrm{LCC}$, large-cell carcinoma. ${ }^{* *} \mathrm{p}<0.001$.

Additional file 6: Figure S2. Impact of CLEC3B expression on OS and DFS in lung cancer patients from the GEO datasets. (a, b) OS survival curves and DFS survival curves of lung cancer patients in GSE30219. $(c, d)$ and in GSE31210. OS, overall survival; DFS, disease-free survival.

Additional file 7: Table S4. Enrichment of GO in the CLEC3B high expression group of ADC

Additional file 8: Table S5. Enrichment of GO in the CLEC3B low expression group of ADC.

Additional file 9: Table S6. Enrichment of GO in the CLEC3B high expression group of SCC.

Additional file 10: Table S7. Enrichment of GO in the CLEC3B low expression group of SCC.

\section{Abbreviations}

CLEC3B: C- type lectin domain family 3 member B; PD-1: Programmed cell death receptor-1; PD-L1: Programmed cell death ligand-1; NSCLC: Nonsmall-cell lung cancer; ADC: Adenocarcinoma; SCC: Squamous cell carcinoma; H-SCORE: Histochemistry score; TCGA: The Cancer Genome Atlas; ESTIMATE: Estimation of Stromal and Immune cells in MAlignant Tumor tissues using Expression data; OS: Overall survival; PFS: Progression-free survival; HR: Hazard ratio; Cls: Confidence intervals; TIMER: Tumor immune estimation resource; GSEA: Gene set enrichment analysis; ROC: Receiver operating characteristic curves; LCC: Large-cell carcinoma; LCNE: Large-cell neuroendocrine tumor; SCLC: Small-cell lung cancer; AUC: Area under the receiver operating characteristic curve; DFS: Disease-free survival.

\section{Acknowledgements}

Not applicable.

\section{Authors' contributions}

HXX designed and managed the entire study; SJX and XT performed the experiments, analyzed the data and wrote the main manuscript text; Jamal, TZB and LXR wrote and revised the manuscript; WYJ and LJY analyzed the data; ZQP provided professional advice about the research. All authors read and approved the final manuscript.

\section{Funding}

This work was supported by the fundamental research funds for the central universities (No. 2042018kf0071) and the Health Commission of Hubei Province joint fund (No. WJ2019H022).

\section{Availability of data and materials}

The datasets used and/or analyzed during the current study are available from the corresponding author upon reasonable request.

\section{Ethics approval and consent to participate}

Not applicable.

\section{Consent for publication}

Not applicable.

\section{Competing interests}

The authors declare that they have no competing interests.

\section{Author details}

1 Department of Blood Transfusion, Zhongnan Hospital of Wuhan University, Wuhan, China. ${ }^{2}$ Department of Immunology, School of Basic Medical Science, Wuhan University, Wuhan, China. ${ }^{3}$ School of Biomedical Sciences, Li Ka Shing Faculty of Medicine, The University of Hong Kong, Hong Kong, China. ${ }^{4}$ Department of Pathology, Zhongnan Hospital of Wuhan University, Wuhan, China.

Received: 1 December 2019 Accepted: 23 March 2020

Published online: 01 April 2020

\section{References}

1. Bray F, Ferlay J, Soerjomataram I, Siegel RL, Torre LA, Jemal A. Global cancer statistics 2018: GLOBOCAN estimates of incidence and mortality worldwide for 36 cancers in 185 countries. CA Cancer J Clin. 2018;68(6):394-424

2. Heuvers ME, Wisnivesky J, Stricker BH, Aerts JG. Generalizability of results from the National Lung Screening Trial. Eur J Epidemiol. 2012;27(9):669-72.

3. Herbst RS, Morgensztern D, Boshoff C. The biology and management of non-small cell lung cancer. Nature. 2018;553(7689):446-54.

4. Lim E, Tay A, Von Der Thusen J, Freidin MB, Anikin V, Nicholson AG. Clinical results of microfluidic antibody-independent peripheral blood circulating tumor cell capture for the diagnosis of lung cancer. J Thorac Cardiovasc Surg. 2014;147(6):1936-8.

5. Hirsch FR, Scagliotti GV, Mulshine JL, Kwon R, Curran WJ Jr, Wu YL, PazAres L. Lung cancer: current therapies and new targeted treatments. Lancet. 2017:389(10066):299-311.

6. Hellmann MD, Nathanson T, Rizvi H, Creelan BC, Sanchez-Vega F, Ahuja A, Ni A, Novik JB, Mangarin LMB, Abu-Akeel M, et al. Genomic features of response to combination immunotherapy in patients with advanced non-small-cell lung cancer. Cancer Cell. 2018;33(5):843-52.

7. Varn FS, Tafe $L$, Amos Cl, Cheng C. Computational immune profiling in lung adenocarcinoma reveals reproducible prognostic associations with implications for immunotherapy. Oncoimmunology. 2018;7(6):e1431084.

8. Dai W, Wang Y, Yang T, Wang J, Wu W, Gu J. Downregulation of exosomal CLEC3B in hepatocellular carcinoma promotes metastasis and angiogenesis via AMPK and VEGF signals. Cell Commun Signal. 2019;17(1):113.

9. Zhu HF, Zhang XH, Gu CS, Zhong Y, Long T, Ma YD, Hu ZY, Li ZG, Wang XY. Cancer-associated fibroblasts promote colorectal cancer progression by secreting CLEC3B. Cancer Biol Ther. 2019;20(7):967-78.

10. Clemmensen I, Petersen LC, Kluft C. Purification and characterization of a novel, oligomeric, plasminogen kringle 4 binding protein from human plasma: tetranectin. Eur J Biochem. 1986;156(2):327-33.

11. Obrist P, Spizzo G, Ensinger C, Fong D, Brunhuber T, Schafer G, Varga M, Margreiter R, Amberger A, Gastl G, et al. Aberrant tetranectin expression in human breast carcinomas as a predictor of survival. J Clin Pathol. 2004;57(4):417-21.

12. Dano K, Behrendt N, Hoyer-Hansen G, Johnsen M, Lund LR, Ploug M, Romer J. Plasminogen activation and cancer. Thromb Haemostat. 2005;93(4):676-81.

13. De Vries TJ, De Wit PE, Clemmensen I, Verspaget HW, Weidle UH, Brocker EB, Ruiter DJ, Van Muijen GN. Tetranectin and plasmin/plasminogen are similarly distributed at the invasive front of cutaneous melanoma lesions. J Pathol. 1996:179(3):260-5.

14. Qadir F, Lalli A, Dar HH, Hwang S, Aldehlawi H, Ma H, Dai H, Waseem A, Teh MT. Clinical correlation of opposing molecular signatures in head and neck squamous cell carcinoma. BMC Cancer. 2019;19(1):830.

15. Liu J, Liu Z, Liu Q, Li L, Fan X, Wen T, An G. CLEC3B is downregulated and inhibits proliferation in clear cell renal cell carcinoma. Oncol Rep. 2018:40(4):2023-35.

16. Chen H, Li H, Zhao J, Peng P, Shao M, Wu H, Wang X, Chen L, Zhang Q, Ruan $Y$, et al. High intratumoral expression of tetranectin associates 
with poor prognosis of patients with gastric cancer after gastrectomy. J Cancer. 2017;8(17):3623-30.

17. Galamb O, Kalmar A, Bartak BK, Patai AV, Leiszter K, Peterfia B, Wichmann $B$, Valcz G, Veres G, Tulassay Z, et al. Aging related methylation influences the gene expression of key control genes in colorectal cancer and adenoma. World J Gastroenterol. 2016;22(47):10325-40.

18. Arellano-Garcia ME, Li R, Liu X, Xie Y, Yan X, Loo JA, Hu S. Identification of tetranectin as a potential biomarker for metastatic oral cancer. Int J Mol Sci. 2010:11(9):3106-21.

19. Deng $X$, Hogdall EV, Hogdall CK, Norgaard-Pedersen B, Jorgensen $M$, Nielsen $H$, Engelholm SA. The prognostic value of pretherapeutic tetranectin and CA-125 in patients with relapse of ovarian cancer. Gynecol Oncol. 2000;79(3):416-9.

20. Yoshihara K, Shahmoradgoli M, Martinez E, Vegesna R, Kim H, TorresGarcia W, Trevino V, Shen H, Laird PW, Levine DA, et al. Inferring tumour purity and stromal and immune cell admixture from expression data. Nat Commun. 2013;4:2612.

21. LiT, Fan J, Wang B, Traugh N, Chen Q, Liu JS, Li B, Liu XS. TIMER: a web server for comprehensive analysis of tumor-infiltrating immune cells. Cancer Res. 2017:77(21):e108-10.

22. Subramanian A, Tamayo P, Mootha VK, Mukherjee S, Ebert BL, Gillette MA, Paulovich A, Pomeroy SL, Golub TR, Lander ES, et al. Gene set enrichment analysis: a knowledge-based approach for interpreting genome-wide expression profiles. P Natl Acad Sci USA. 2005;102(43):15545-50.

23. Nagy A, Lanczky A, Menyhart O, Gyorffy B. Validation of miRNA prognostic power in hepatocellular carcinoma using expression data of independent datasets. Sci Rep. 2018;8:9227.

24. Li B, Severson E, Pignon JC, Zhao H, Li T, Novak J, Jiang P, Shen H, Aster JC, Rodig S, et al. Comprehensive analyses of tumor immunity: implications for cancer immunotherapy. Genome Biol. 2016;17(1):174.

25. Schmidt M, Bohm D, von Torne C, Steiner E, Puhl A, Pilch H, Lehr HA, Hengstler JG, Kolbl H, Gehrmann M. The humoral immune system has a key prognostic impact in node-negative breast cancer. Cancer Res. 2008;68(13):5405-13.

26. Lohr M, Edlund K, Botling J, Hammad S, Hellwig B, Othman A, Berglund A, Lambe M, Holmberg L, Ekman S, et al. The prognostic relevance of tumour-infiltrating plasma cells and immunoglobulin kappa $\mathrm{C}$ indicates an important role of the humoral immune response in non-small cell lung cancer. Cancer Lett. 2013;333(2):222-8.

27. Marshall EA, Ng KW, Kung SH, Conway EM, Martinez VD, Halvorsen EC, Rowbotham DA, Vucic EA, Plumb AW, Becker-Santos DD, et al. Emerging roles of T helper 17 and regulatory $T$ cells in lung cancer progression and metastasis. Mol Cancer. 2016;15(1):67.

28. Stankovic B, Bjorhovde HAK, Skarshaug R, Aamodt H, Frafjord A, Muller E, Hammarstrom C, Beraki K, Baekkevold ES, Woldbaek PR, et al. Immune cell composition in human non-small cell lung cancer. Front Immunol. 2018:9:3101.

29. Wang SS, Liu W, Ly D, Xu H, Qu L, Zhang L. Tumor-infiltrating B cells: their role and application in anti-tumor immunity in lung cancer. Cell Mol Immunol. 2019;16(1):6-18.

30. Backman M, La Fleur L, Kurppa P, Djureinovic D, Elfving H, Brunnstrom $H_{\text {, }}$ Mattsson JSM, Ponten V, Eltahir M, Mangsbo S et al. Characterization of patterns of immune cell infiltration in NSCLC. J Thorac Oncol. 2020. https ://doi.org/10.1016/j.jtho.2019.12.127.

31. Lundgren S, Elebro J, Heby M, Nodin B, Leandersson K, Micke P, Jirstrom K, Mezheyeuski A. Quantitative, qualitative and spatial analysis of lymphocyte infiltration in periampullary and pancreatic adenocarcinoma. Int J Cancer. 2020. https://doi.org/10.1002/ijc.32945.

32. Torre LA, Siegel RL, Jemal A. Lung cancer statistics. Adv Exp Med Biol. 2016:893:1-19.
33. Cao R, Wu Q, Li Q, Yao M, Zhou H. A 3-mRNA-based prognostic signature of survival in oral squamous cell carcinoma. Peerj. 2019;7:e7360.

34. Camidge DR, Doebele RC, Kerr KM. Comparing and contrasting predictive biomarkers for immunotherapy and targeted therapy of NSCLC. Nat Rev Clin Oncol. 2019;16(6):341-55.

35. Carbone DP, Gandara DR, Antonia SJ, Zielinski C, Paz-Ares L. Non-smallcell lung cancer: role of the immune system and potential for immunotherapy. J Thorac Oncol. 2015;10(7):974-84.

36. Altorki NK, Markowitz GJ, Gao D, Port JL, Saxena A, Stiles B, McGraw T, Mittal V. The lung microenvironment: an important regulator of tumour growth and metastasis. Nat Rev Cancer. 2019;19(1):9-31.

37. Muppa P, Parrilha Terra SBS, Sharma A, Mansfield AS, Aubry MC, Bhinge K, Asiedu MK, de Andrade M, Janaki N, Murphy SJ, et al. Immune cell infiltration may be a key determinant of long-term survival in small cell lung cancer. J Thorac Oncol. 2019;14(7):1286-95.

38. Zhang J, Wang J, Qian Z, Han Y. CCR5 is associated with immune cell infiltration and prognosis of lung cancer. JThorac Oncol. 2019;14(5):e102-3.

39. Wang JB, Huang $X$, Li FR. Impaired dendritic cell functions in lung cancer: a review of recent advances and future perspectives. Cancer Commun. 2019;39(1):43

40. Wculek SK, Cueto FJ, Mujal AM, Melero I, Krummel MF, Sancho D. Dendritic cells in cancer immunology and immunotherapy. Nat Rev Immunol. 2019.

41. Zhang J, Endres S, Kobold S. Enhancing tumor T cell infiltration to enable cancer immunotherapy. Immunotherapy. 2019;11(3):201-13.

42. Edlund K, Madjar K, Mattsson JSM, Djureinovic D, Lindskog C, Brunnstrom $\mathrm{H}$, Koyi H, Branden E, Jirstrom K, Ponten F, et al. Prognostic impact of tumor cell programmed death ligand 1 expression and immune cell infiltration in NSCLC. J Thorac Oncol. 2019;14(4):628-40.

43. Mei J, Xiao Z, Guo C, Pu Q, Ma L, Liu C, Lin F, Liao H, You Z, Liu L. Prognostic impact of tumor-associated macrophage infiltration in non-small cell lung cancer: a systemic review and meta-analysis. Oncotarget. 2016;7(23):34217-28.

44. Bercovici N, Guerin MV, Trautmann A, Donnadieu E. The remarkable plasticity of macrophages: a chance to fight cancer. Front Immunol. 2019;10:1563.

45. Rakaee M, Busund LR, Jamaly S, Paulsen EE, Richardsen E, Andersen S, Al-Saad S, Bremnes RM, Donnem T, Kilvaer TK. Prognostic value of macrophage phenotypes in resectable non-small cell lung cancer assessed by multiplex immunohistochemistry. Neoplasia. 2019:21(3):282-93.

46. Meng $X$, Gao Y, Yang L, Jing H, Teng F, Huang Z, Xing L. Immune microenvironment differences between squamous and non-squamous nonsmall-cell lung cancer and their influence on the prognosis. Clin Lung Cancer. 2019;20(1):48-58.

47. Sun X, Xin Y, Wang M, Li S, Miao S, Xuan Y, Wang Y, Lu T, Liu J, Jiao W. Overexpression of long non-coding RNA KCNQ1OT1 is related to good prognosis via inhibiting cell proliferation in non-small cell lung cancer. Thorac Cancer. 2018;9(5):523-31.

\section{Publisher's Note}

Springer Nature remains neutral with regard to jurisdictional claims in published maps and institutional affiliations.

Ready to submit your research? Choose BMC and benefit from:

- fast, convenient online submission

- thorough peer review by experienced researchers in your field

- rapid publication on acceptance

- support for research data, including large and complex data types

- gold Open Access which fosters wider collaboration and increased citations

- maximum visibility for your research: over 100M website views per year

At BMC, research is always in progress.

Learn more biomedcentral.com/submissions 